\title{
DYNAMICS OF CERTAIN CHEMICAL COMPONENTS IN TOMATO FRUIT (LYCOPERSICON ECULENTUM MILL.) MAINTAINED AT DIFFERENT TEMPERATURES AFTER HARVEST
}

\author{
Sándor Rózsa ${ }^{1, *}$, Dănuț-Nicolae Măniuțiu ${ }^{1}$, Vasile Lazăr ${ }^{1}$, Tincuța-Marta Gocan ${ }^{1}$, Ileana Andreica ${ }^{1}$, \\ Emese Egyed ${ }^{1}$, Gheorghe Poșta ${ }^{2, *}$ \\ ${ }^{1}$ University of Agricultural Sciences and Veterinary Medicine, \\ Faculty of Horticulture, 400372, 3-5 Mănăştur Street, Cluj-Napoca, Romania \\ 2 Banat University of Agricultural Sciences and Veterinary Medicine „King Michael I of Romania" from Timisoara, \\ Faculty of Horticulture and Forestry, 119 Aradului Street, 300645 Timisoara, Romania
}

\section{Current Trends in}

Natural Sciences

\begin{abstract}
Traditional tomato varieties are of particular importance for vegetable cultivation, by capitalizing on the diversity of local populations and increasing the number of crops. The study of local populations of cultivated tomatoes determines the accumulation of additional knowledge on how the shape, size and taste of fruits evolve, helping to identify new varieties with a role in improving the productivity, quality and nutritional value of tomatoes. In this paper, 2 local varieties from the Cluj County area were studied, from the point of view of the dynamics of certain chemical components when, after harvest, the tomatoes are stored at different stages of maturity. The lowest water loss, of $7.5 \%$, was presented by the pink variety, stored for 7 days at a temperature of $8{ }^{\circ} \mathrm{C}$. Vitamin $C$ was better preserved in the case of the red variety, presenting after 7 days of storage at $8{ }^{\circ} \mathrm{C}$, values of $27.23 \%$ at green maturity and $46.58 \%$ at consumption maturity. The pectic substances, in the case of the studied varieties, do not show significant variations depending on the maturity phase or the storage method, these registering values between 0.11 and $0.27 \%$.
\end{abstract}

Keywords: C vitamin, pectic substances, soluble dry matter, tomatoes.

\section{INTRODUCTION}

Vegetable cultivation is an important branch of agri-food production and is an important sector for both the national economy in general and the agricultural economy in particular (Hoza et al., 2018). Vegetable growing is important for producers, processors, traders, and last but not least for consumers who are increasingly concerned about the food quality of vegetables and the technological features that ensure their superior quality (Ciofu et al., 2004; de Jesus et al., 2011).

At a time when there is a need to increase the production and consumption of vegetables in general in a fresh state in order to ensure safe agri-food products for human consumption, the research will address the improvement of technologies for growing tomatoes in solariums with the aim of resulting in an increase in the quantitative and qualitative level of production (Helyes et al., 2006). Solarium cultivation is a necessity to ensure the consumption of fresh vegetables because 
vegetables are vegetable products with a rich content of vitamins, minerals and bioactive substances (Jiang et al., 2020).

Tomatoes are one of the most valuable vegetables in terms of food (Beaulieu and Saltevit, 1997). The qualities they possess have made them consumed in the most varied regions of the world, even where they are not cultivated. The increase in tomato consumption is due to the fact that these vegetables have a very pleasant taste and a wide range of uses (fresh, in the form of tomato salad or mixed with other vegetables, soups, broth, pots, sauces, stuffed tomatoes etc). (Wang et al., 2011). Unripe fruits ("gogonele") or semi-ripe fruits are used to prepare tasty pickles or canned vegetables (Pinheiro et al., 2015). It is also preparing more and more tomato juice which, in addition to its special nutritional value, is a real refreshment in hot weather (Lopez and Gomez, 2004). Tomato juice is widely consumed by dieters, especially those suffering from gastric disorders (Hatmani et al. 2012). Vitaminized tomato juice, previously diluted, is administered to infants, being considered superior to orange juice (Stevens, 1985). Prepared with lemon, salt and pepper, in some countries such as France and Italy it is a drink highly appreciated by adults, surpassing many other soft drinks (Tilahun et al., 2019).

The high nutritional value of tomatoes also results from the fact that this vegetable is consumed a lot in the raw state, so that the vitamins and mineral salts it contains are used almost entirely by the body (Teka, 2013). From the point of view of nutritional value, the content of sugar (about 3-4\%), C vitamin (20-60 mg per $100 \mathrm{~g}$ ) and A vitamin (2-6 mg) and less of their energy value are of primary interest, which is quite low (176 calories) compared to other foods (Park et al., 2005; Sirisomboon et al., 2012). We must not overlook the favorable proportion of amino acids and organic acids found in tomato fruit, as well as the salts of magnesium, sodium, potassium and iron which are also found in an appropriate percentage for the proper functioning of the human body (Heuvelink, 2005).

Local tomato varieties that have been maintained and perpetuated over the years are an important source of germplasm for tomato growers in certain areas (de Luna et al., 2020).

In this paper, the behaviour of two local varieties of tomatoes from Cluj County, Romania was maintained at different temperatures after harvest, in terms of the dynamics of certain chemical components, given that some smaller local producers do not refrigerate tomatoes after harvesting, but keeps them in environmental conditions until capitalization.

\section{MATERIALS AND METHODS}

The biological material used in the experiment was represented by two local tomato genotypes, from Aghireșu-Fabrici locality (N 46.8660, E 23.2743), Cluj County, Romania presenting the following morphological characters:

Genotype 1 - 'Red Granny'

The plant has indeterminate growth, is tall, vigorous, with rich shoots. The leaf is ordinary, slightly embossed, green. The inflorescence is compound and the shape of the bunch is semi-compact. Forms on average 5-7 fruits per inflorescence. The fruit is round-flattened with a slightly wrinkled surface. Before ripening, the fruit is coloured dark green, and at technical maturity it becomes dark red, without green spots near the stylistic point. The average weight of a fruit varies between 350650 grams, having 7-12 seminal lodges. It is an early variety (102-105 days the vegetation period from the appearance of the cotyledon leaves). The fruit has a sweet-sour taste and has a moderate resistance to transport, being indicated both for fresh consumption and for industrialization.

Genotype 2 - 'Pink Granny' 


\begin{tabular}{|c|c|}
\hline \multicolumn{2}{|c|}{$\begin{array}{c}\text { Current Trends in Natural Sciences } \\
\text { Vol. 10, Issue 19, pp. 313-320, } 2021 \\
\text { https://doi.org/10.47068/ctns.2021.v10i19.040 }\end{array}$} \\
\hline $\begin{array}{l}\text { Current Trends in Natural Sciences (on-line) } \\
\text { ISSN: 2284-953X } \\
\text { ISSN-L: 2284-9521 }\end{array}$ & $\begin{array}{r}\text { Current Trends in Natural Sciences (CD-Rom) } \\
\text { ISSN: 2284-9521 } \\
\text { ISSN-L: 2284-9521 }\end{array}$ \\
\hline
\end{tabular}

The plant has indeterminate growth, is tall, vigorous, with medium shoots. The leaf is ordinary, slightly corrugated, light green. The inflorescence is compound, and its shape is a loose top and forms on average 4-6 fruits. The fruit is round-flattened with a slightly wrinkled surface. Before ripening, the fruit is coloured light green, and at technical maturity it turns pink, without green spots near the stylistic point. The average weight of a fruit varies between $250-450$ grams, having 6-10 seminal lodges. It is an early variety because it has a 95-100-day vegetation period from the appearance of the cotyledon leaves to the formation of the first fruit. The fruit has a sweet taste and has a moderate resistance to transport and is more suitable for fresh consumption, but can also be industrialized.

The definition of the maturity phases was made according to the methodology envisaged in the literature (figure 1), as follows (de Jesus et al., 2011):

MP1 - green maturity - the surface of the fruit is light green, evenly distributed;

MP2 - half ripening - yellowish coloration intensifies and spreads on about $50 \%$ of the fruit surface; MP3 - ripening - the surface of the fruit is coloured entirely in pink-yellow or red-yellow depending on the genotype;

MP4 - consumption maturity - the surface of the fruit is coloured entirely pink or red depending on the genotype.

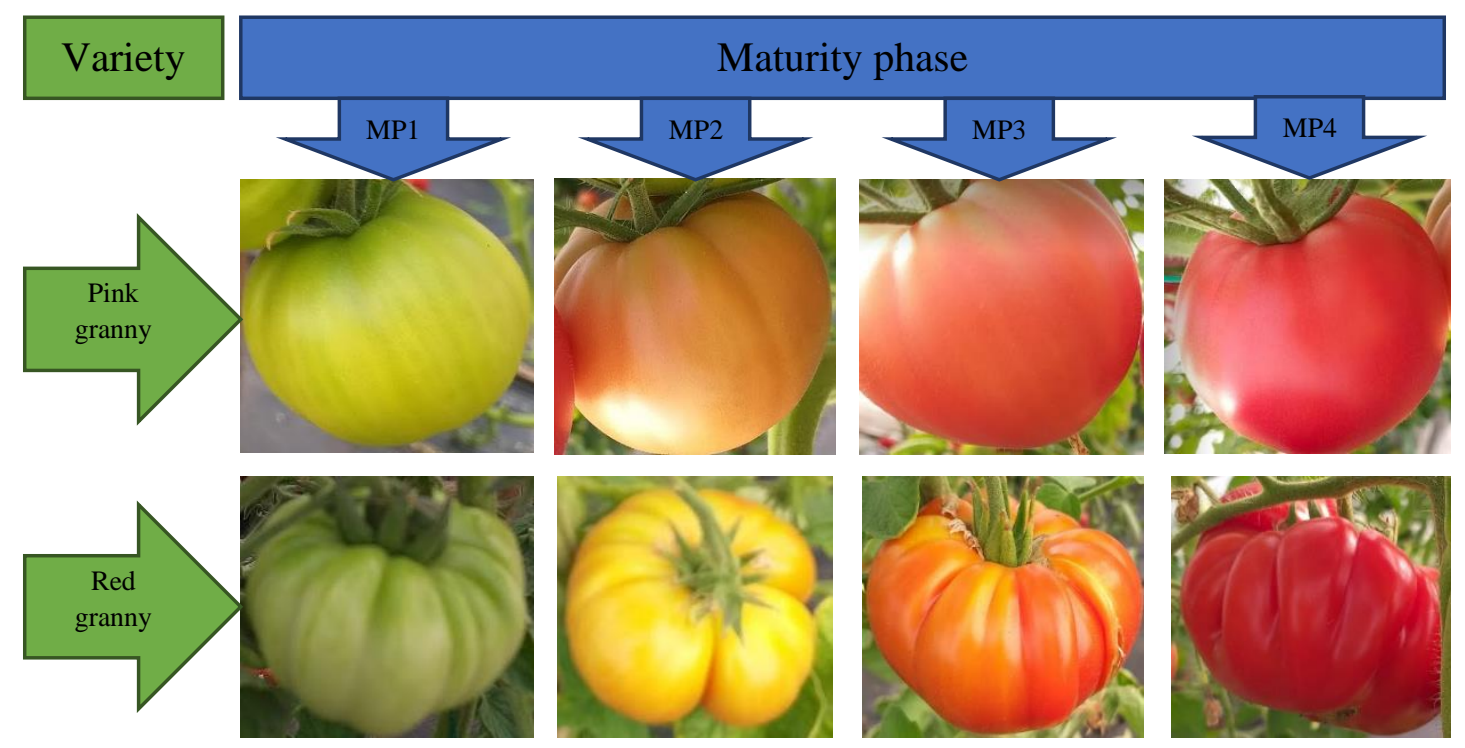

Figure 1. Maturity phases at the studied genotypes

Chemical determinations were performed immediately after harvest and were repeated after 7 days of storage under experimental conditions, at $8 \pm 1{ }^{\circ} \mathrm{C}$ and $20 \pm 1{ }^{\circ} \mathrm{C}$ (Sirisomboon et al., 2012).

The soluble dry matter was determined using the Abbe refractometer, model LEOI-112 (Rozsa et al., 2020).

$\mathrm{C}$ vitamin was determined by the iodometric method using iodine as an oxidant, resulting from the reaction between potassium iodate and potassium iodine in an acidic medium (hydrochloric acid).

The determination of pectic substances was performed by gravimetric method. Pectin was extracted from the plant material and saponified. It precipitates as calcium pectate by adding calcium chloride to an acidic solution. After a thorough wash to remove chlorine ions, the precipitate is dried and weighed (Rozsa et al., 2020). 


\section{RESULTS AND DISCUSSIONS}

Following the evolution of the soluble dry matter from the samples collected (table 1, figure 2), it can be seen that the red variety has a $11.45 \%$ higher amount of soluble dry matter than the pink variety.

Table 1. Evolution of dry matter soluble in the tomato genotypes studied, on maturity stages and storage conditions

\begin{tabular}{|c|c|c|c|c|c|c|}
\hline \multirow[b]{2}{*}{$\begin{array}{c}\text { Maturity } \\
\text { phase }\end{array}$} & \multicolumn{3}{|c|}{ PINK GRANNY } & \multicolumn{3}{|c|}{ RED GRANNY } \\
\hline & $\begin{array}{c}\text { DM }(\%) \\
\text { at } \\
\text { harvesting }\end{array}$ & $\begin{array}{c}\text { DM (\%) } \\
\text { after } 7 \text { days } \\
\text { of storage at } \\
8 \pm 1^{\circ} \mathrm{C}\end{array}$ & $\begin{array}{c}\text { DM (\%) } \\
\text { after } 7 \text { days } \\
\text { of storage at } \\
20 \pm 1^{\circ} \mathrm{C}\end{array}$ & $\begin{array}{c}\text { DM (\%) } \\
\text { at } \\
\text { harvesting }\end{array}$ & $\begin{array}{c}\text { DM (\%) } \\
\text { after } 7 \text { days } \\
\text { of storage at } \\
8 \pm 1^{\circ} \mathrm{C}\end{array}$ & $\begin{array}{c}\text { DM (\%) } \\
\text { after } 7 \text { days } \\
\text { of storage at } \\
20 \pm 1^{\circ} \mathrm{C}\end{array}$ \\
\hline MP1 & 5.15 & 5.54 & 6.05 & 6.03 & 6.72 & 7.02 \\
\hline MP1--->MP2 & 5.45 & 5.94 & 6.46 & 6.22 & 6.94 & 7.28 \\
\hline MP2 & 5.55 & 6.13 & 6.63 & 6.35 & 7.10 & 7.48 \\
\hline MP2--->MP3 & 5.75 & 6.44 & 6.93 & 6.47 & 7.31 & 7.67 \\
\hline MP3 & 5.95 & 6.74 & 7.21 & 6.59 & 7.43 & 7.85 \\
\hline MP3--->MP4 & 6.05 & 6.93 & 7.38 & 6.72 & 7.55 & 8.05 \\
\hline MP4 & 6.17 & 7.10 & 7.59 & 6.85 & 7.69 & 8.26 \\
\hline
\end{tabular}

In the case of the 'Pink Granny' tomato genotype, the fruits show 5.15\% DM at the green ripeness phase MP1, reaching 6.17\% DM at the consumption phase MP4. Stored at a temperature of $8{ }^{\circ} \mathrm{C}$ for 7 days, they show an increase in soluble dry matter between $7.5 \%$ at the green maturity phase MP1, reaching a $15 \%$ increase at the consumption maturity phase MP4. If pink tomatoes are stored at a temperature of $20{ }^{\circ} \mathrm{C}$ for 7 days, they show an increase in DM by $17.5 \%$ in the green maturity phase MP1, reaching $23 \%$ in the consumption maturity phase.

In comparison, the fruits from the 'Red Granny' genotype show $6.03 \% \mathrm{DM}$ at the green ripeness phase MP1, reaching 6.85\% DM at the consumption phase of MP4. Stored at a temperature of $8{ }^{\circ} \mathrm{C}$ for 7 days, they show an increase of soluble dry matter between $11.5 \%$ at the green maturity phase MP1, reaching a $12.3 \%$ increase at the consumption maturity phase MP4. If the tomatoes of the 'Red granny' genotype are kept at a temperature of $20{ }^{\circ} \mathrm{C}$ for 7 days, they show an increase in DM by $16.5 \%$ in the green maturity phase MP1, reaching $20.55 \%$ in the consumption maturity phase.

Figure 2 presents the synthesis of comparisons regarding the evolution of DM in the studied samples, by maturity phases and storage conditions.

Based on the comparative analysis of the experimental results presented in Table 1 and Figure 2, it can be seen that the highest moisture loss is the genotype 'Pink Granny' with an average water loss of $20.31 \%$ when stored at $20{ }^{\circ} \mathrm{C}$, compared to the 'Red Granny' genotype, which has a loss of only $18.44 \%$, in the same storage conditions. In the case of keeping the tomato fruits at a temperature of $8{ }^{\circ} \mathrm{C}$, the moisture losses are similar in both genotypes, the registration values being $11.67 \%$ in 'Pink Granny', respectively $12.16 \%$ in 'Red Granny' genotype.

In the case of the $\mathrm{C}$ vitamin content of tomato fruits, it was followed its connection with the soluble dry matter, on each phase of maturity studied, as well as on the chosen storage conditions. 


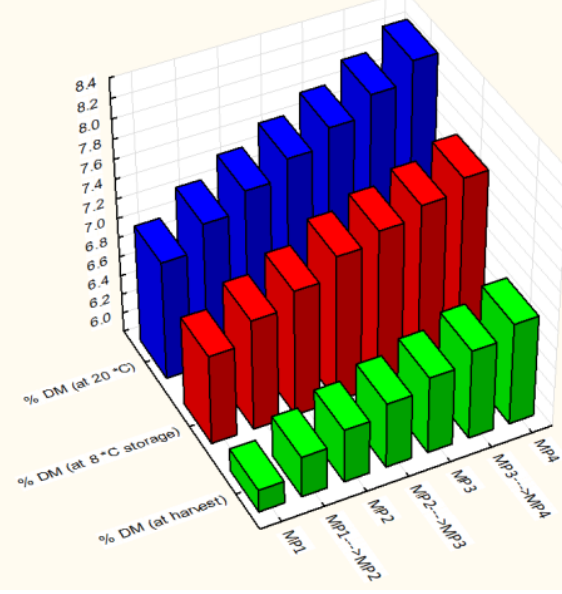

Figure 2. Synthesis of comparisons regarding the evolution of DM in the studied samples, by maturity phases and storage conditions

Thus, in figure 3 are presented the correlation graphs between the soluble dry matter and the content of $\mathrm{C}$ vitamin, for the 'Pink Granny' tomato genotype, by maturity phases and chosen storage conditions.
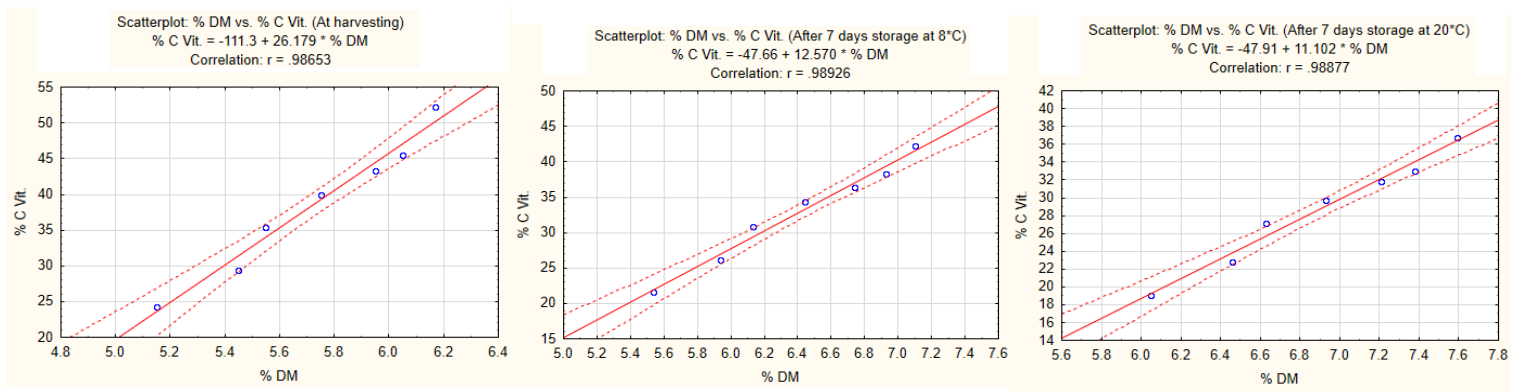

Figure 3. Correlations between DM and C vitamin content, in the case of the 'Pink granny' tomato genotype

In the 'Pink Granny' tomato genotype, the correlation coefficient (r) between the soluble dry matter and $\mathrm{C}$ vitamin content varied between 0.98653 at harvest, 0.98926 at 7 days of storage at $8{ }^{\circ} \mathrm{C}$ and 0.98877 at 7 days storage at $20^{\circ} \mathrm{C}$. Comparing these values of the correlations with the probability coefficient of $5 \% \mathrm{r}=0.50$ it can be said that the correlation coefficient between the soluble dry matter and the content in $\mathrm{C}$ vitamin, to the 'Pink Granny' tomato genotype, for each phase of maturity and for all the chosen storage conditions, it is very significantly positive.

Also, in figure 4 are presented the correlation graphs between the soluble dry matter and the content of C vitamin, for the 'Red Granny' tomato genotype, by maturity phases and chosen storage conditions.

In the case of the 'Red Granny' tomato genotype, the correlation coefficient (r) between the soluble dry matter and $\mathrm{C}$ vitamin content varied between 0.95264 at harvest, 0.94531 at 7 days of storage at $8{ }^{\circ} \mathrm{C}$ and 0.95530 at 7 days storage at $20{ }^{\circ} \mathrm{C}$. Comparing these correlation values with the probability coefficient of $5 \% \mathrm{r}=0.50$ it can be said that the correlation coefficient between the soluble dry matter and C vitamin content, in the case of 'Red Granny' tomato genotype, for each phase of maturity and for all chosen storage conditions, it is very significantly positive. 

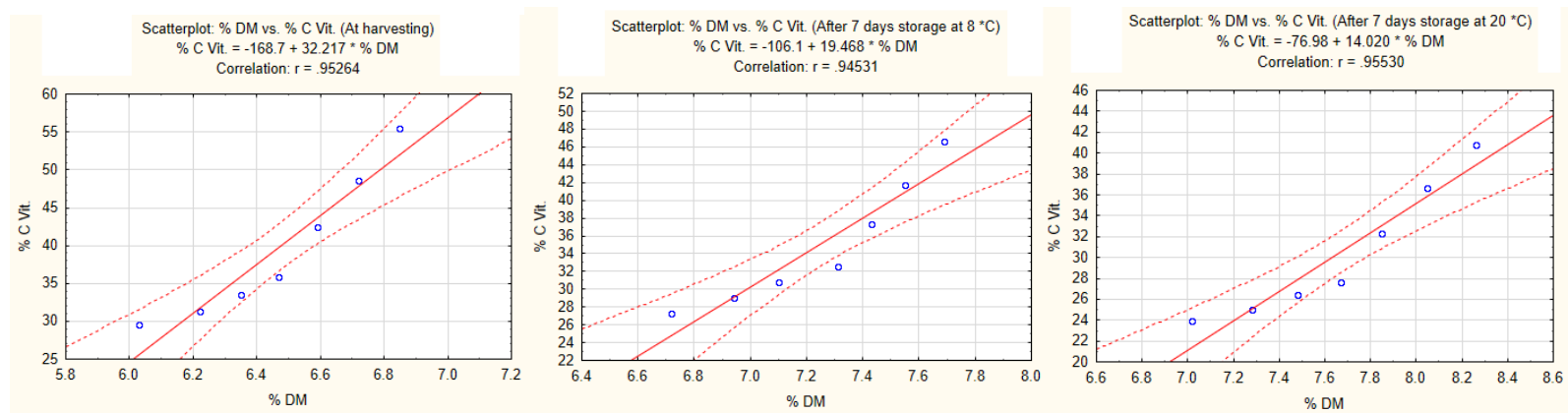

Figure 4. Correlations between DM and C vitamin content, in the case of 'Red Granny' tomato genotype

In the case of pectic substances, their connection with the soluble dry matter was followed, on each studied maturity phase, as well as on the chosen storage conditions. For details, figure 5 shows the correlation graphs between the soluble dry matter and the pectic content, in the case of the 'Pink Granny' genotype, by maturity stages and selected storage conditions.
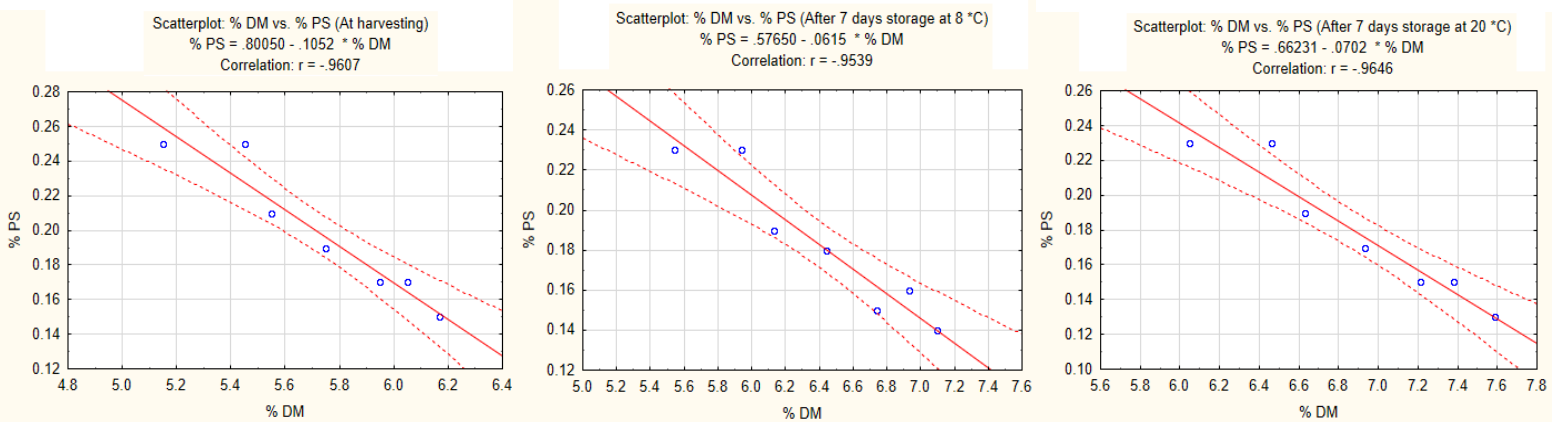

Figure 5. Correlations between DM and pectic content, in the case of the 'Pink Granny' tomato genotype

The correlation coefficient (r) between the soluble dry matter and the pectic content, ranged in tomato fruit of the 'Pink Granny' genotype between 0.9607 at harvest, 0.9539 at 7 days of storage at $8{ }^{\circ} \mathrm{C}$ and 0.9646 at 7 days storage at $20{ }^{\circ} \mathrm{C}$. Comparing these correlation values with the probability coefficient of $5 \% \mathrm{r}=0.50$ it can be said that the correlation coefficient between the soluble dry matter and the pectic content, in the case of the 'Pink Granny' genotype, for each phase of maturity and for all chosen storage conditions, is very significant positive. This significance also results from the loss of water during fruit ripening and during storage.

Figure 6 shows the correlation graphs between the soluble dry matter and the pectic content, for the 'Red Granny' genotype, by maturity stages and selected storage conditions.
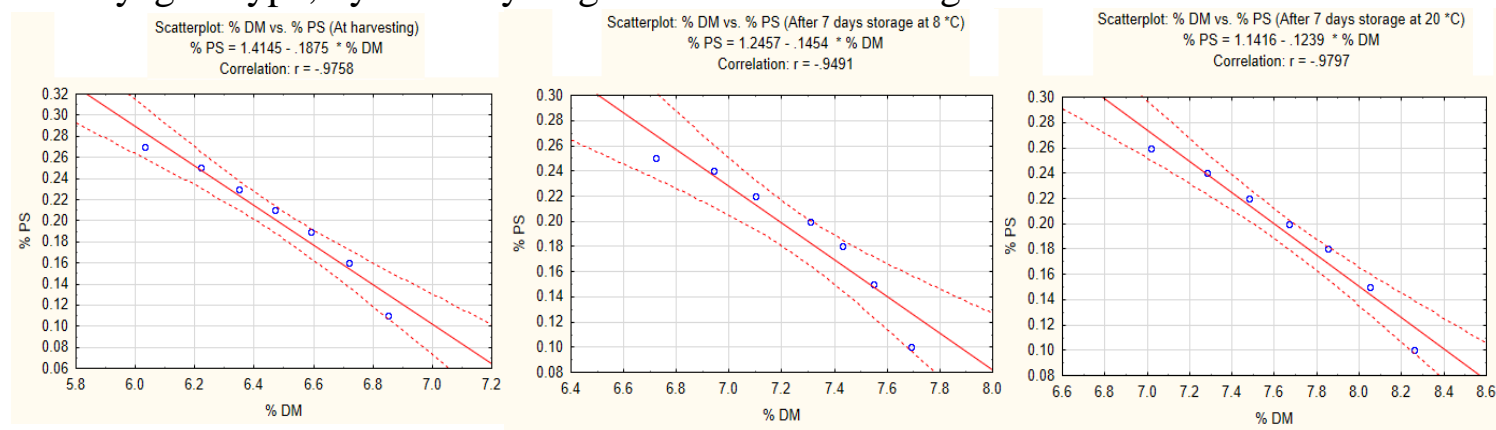

Figure 6. Correlation between DM and pectic content, in the case of 'Red Granny' tomato genotype 
In comparison, for the 'Red Granny' tomato genotype, the correlation coefficient ( $\mathrm{r}$ ) between soluble dry matter and pectic content ranged from 0.9758 at harvest to 0.9491 at 7 days of storage at $8{ }^{\circ} \mathrm{C}$, and 0.9797 at 7 days storage at $20{ }^{\circ} \mathrm{C}$. Comparing these correlation values with the probability coefficient of $5 \% \mathrm{r}=0.50$ it can be said that the correlation coefficient between the soluble dry matter and the pectic content, in the case of the 'Red Granny' genotype, for each phase of maturity and for all chosen storage conditions, is very significant positive. And in this case, this significance also results from the loss of water during fruit ripening and during storage.

\section{CONCLUSIONS}

Following the dynamics of the soluble dry matter evolution in tomato fruits from the two studied genotypes, depending on the maturity phase at which the harvest was carried out, the 'Red Granny' genotype has higher DM values for each harvest phase compared to the 'Pink Granny' genotype.

Storing the tomato fruit at a temperature of $20^{\circ} \mathrm{C}$ for 7 days, determines in the case of 'Pink Granny' genotype an increase of $1.17 \%$ DM compared to harvest time, and when stored at $8{ }^{\circ} \mathrm{C}$ for 7 days, it shows a $0.68 \%$ increase in DM.

Following the correlations made, it can be stated that there is a close link between the soluble dry matter and the $\mathrm{C}$ vitamin and pectic substances content, for each maturity phase and applied storage conditions.

\section{REFERENCES}

Beaulieu, J. C., \& Saltveit, M. E. (1997). Inhibition or promotion of tomato fruit ripening by acetaldehyde and ethanol is concentration dependent and varies with initial fruit maturity. Journal of the American Society for Horticultural Science, 122(3), 392-398.

Ciofu, R., Stan, N., Popescu V., Chilom, P., Apahidean, S., Horgoş, A., Berar, V., Lauer, K. F., Atanasiu, N. (2004). Tratat de Legumicultură [Treatise on Vegetable Culture], Ed. Ceres, Bucureşti

de Jesús Dávila-Aviña, J. E., Villa-Rodríguez, J., Cruz-Valenzuela, R., Rodríguez-Armenta, M., Espino-Díaz, M., Ayala-Zavala, J. F., ... \& González-Aguilar, G. (2011). Effect of edible coatings, storage time and maturity stage on overall quality of tomato fruits. American Journal of Agricultural and Biological Sciences, 6(1), 162-171.

de Luna, R. G., Dadios, E. P., Bandala, A. A., \& Vicerra, R. R. P. (2020). Tomato growth stage monitoring for smart farm using deep transfer learning with machine learning-based maturity grading. Agrivita, 42(1), 24.

Hatami, M., KalantarI, S., \& Delshad, M. (2012, June). Responses of different maturity stages of tomato fruit to different storage conditions. In VII International Postharvest Symposium 1012 (pp. 857-864).

Helyes, L., Pék, Z., \& Lugasi, A. (2006). Tomato fruit quality and content depend on stage of maturity. HortScience, 41(6), 1400-1401.

Heuvelink, E. (Ed.). (2005). Tomatoes (Vol. 13). CABI.

Hoza, G., Dinu, M., Soare, R., Becherescu, A. D., Apahidean, I. A., \& Hoza, D. (2018). Influence of plant management systems on growth and fructification of tomato plants in protected culture. Scientific Papers. Series B. Horticulture, 62, 457-462.

Jiang, Y., Bian, B., Wang, X., Chen, S., Li, Y., \& Sun, Y. (2020). Identification of tomato maturity based on multinomial logistic regression with kernel clustering by integrating color moments and physicochemical indices. Journal of Food Process Engineering, 43(10), e13504.

López Camelo, A. F., \& Gómez, P. A. (2004). Comparison of color indexes for tomato ripening. Horticultura Brasileira, 22(3), 534-537.

Park, S., Ko, E., Lee, M., \& Hong, S. (2005). Fruit quality of'York'tomato as influenced by harvest maturity and storage temperature. Korean Journal of Horticultural Science \& Technology, 23(1), 31-37.

Pinheiro, J., Alegria, C., Abreu, M., Sol, M., Gonçalves, E. M., \& Silva, C. L. (2015). Postharvest Quality of Refrigerated Tomato Fruit ( $\mathrm{S}$ olanum lycopersicum, cv. Z inac) at Two Maturity Stages Following Heat Treatment. Journal of Food Processing and Preservation, 39(6), 697-709.

Rózsa S., Lazăr V., Gocan T.M. (2020) Tehnologia produselor horticole 2 - Îndrumător de lucrări practice [Horticultural technology 2 - Practical work guide], Editura AcademicPres, Cluj-Napoca. 


\section{Current Trends in Natural Sciences}

Vol. 10, Issue 19, pp. 313-320, 2021

https://doi.org/10.47068/ctns.2021.v10i19.040

Current Trends in Natural Sciences (on-line)

ISSN: 2284-953X

Current Trends in Natural Sciences (CD-Rom)

ISSN: 2284-9521

ISSN-L: 2284-9521

ISSN-L: 2284-9521

Sirisomboon, P., Tanaka, M., \& Kojima, T. (2012). Evaluation of tomato textural mechanical properties. Journal of Food Engineering, 111(4), 618-624.

Stevens, M. A. (1985). Tomato flavor: effects of genotype, cultural practices, and maturity at picking. In Evaluation of quality of fruits and vegetables (pp. 367-386). Springer, Boston, MA.

Teka, T. A. (2013). Analysis of the effect of maturity stage on the postharvest biochemical quality characteristics of tomato (Lycopersicon esculentum Mill.) fruit. International Research Journal of Pharmaceutical and Applied Sciences, 3(5), 180-186.

Tilahun, S., Park, D. S., Solomon, T., Choi, H. R., \& Jeong, C. S. (2019). Maturity stages affect nutritional quality and storability of tomato cultivars. CyTA-Journal of Food, 17(1), 87-95.

Wang, X., Mao, H., Han, X., \& Yin, J. (2011). Vision-based judgment of tomato maturity under growth conditions. African Journal of Biotechnology, 10(18), 3616-3623. 